\title{
"Cuerpos precarios": Habitar, respirar y trabajar en el sur global. Una mirada desde la sociología de los cuerpos/emociones
}

\author{
"Precarious bodies»: Inhabit, breathe and work in the global \\ south. A look from the sociology of bodies / emotions
}

\author{
Ana Lucía Cervio (CONICET-CICLOP-UBA/ CIES) \\ Pedro Lisdero (CONICET-CIECS-UNC/CIES) \\ Victoria D'hers (CONICET- IIGG-UBA/CIES)
}

anacervio@hotmail.com (ARGENTINA)

Recibido: 21.122018

Aceptado: 13.11.2019

\section{RESUMEN}

Este artículo se propone establecer algunas conexiones y discusiones en torno al riesgo, la incertidumbre y la precariedad como categorías clave para el análisis de conflictos sociales en escenarios urbanos del Sur Global. Particularizando la mirada en procesos colectivos ligados al habitar, el trabajo y el ambiente, desde una Sociología de los Cuerpos/Emociones, se busca reponer algunas de las formas en las que el riesgo y la incertidumbre moldean "cuerpos precarios" en la actual fase de acumulación capitalista. En base al análisis cualitativo de material empírico colectado, se mapean algunas de las formas en que el riesgo, la incertidumbre y la precariedad se materializan en las prácticas, experiencias y emociones de los sujetos.

Para alcanzar dicho objetivo, se ha seleccionado la siguiente estrategia expositiva. En primer lugar, se presenta una breve sistematización de las nociones de riesgo, incertidumbre y precariedad, recuperando los principales aportes efectuados desde las Ciencias Sociales. Sobre esta base, se plantea una aproximación teórica a los "cuerpos precarios", enfatizando la relevancia de una mirada desde la conflictividad social. En segundo lugar, se sintetizan escenas conflictuales seleccionadas en torno al habitar, el ambiente y el trabajo que han tenido lugar en los últimos años en contextos urbanos de Argentina, estableciendo enlaces teóricos con las nociones de riesgo, incertidumbre y precariedad desde una Sociología de los Cuerpos/Emociones. Finalmente, a modo de conclusión, se abren algunas pistas que señalan la relevancia teórico-epistemológica de observar el 
conflicto como un modo de acercamiento a las "sociedades del riesgo", indicando ciertos sentidos en que la habitabilidad, el ambiente y el trabajo configuran marcas en los "cuerpos precarios" del Sur Global en el siglo XXI

\title{
PALABRAS CLAVE
}

Riesgo, incertidumbre, precariedad, conflictos, cuerpos/emociones.

\begin{abstract}
This article aims at making some connections and raising the issues regarding risk, uncertainty and precariousness as key categories to analyze social conflict in Global South sceneries. Pointing at collective processes linked to inhabiting, working and living in polluted environments, from a Sociology of Bodies/Emotions we pretend to clarify some of the ways in which risk and uncertainty shape "precarious bodies" in the current phase of capitalist accumulation. In base of an analysis of qualitative empirical material, how risk uncertainty and precariousness became materialized in practices, experiences and emotions is displayed.

To reach that objective, the following strategy is followed: First, a brief systematisation of the concepts of risk, uncertainty and precariousness is presented, going over the main findings made in Social Sciences. Then, a theoretical approach on precarious bodies is laid out, stressing its link to a perspective from social conflict. Secondly, some conflict scenes on habitat, environment and labour in urban context are summarised, then connecting them to the notions of risk, uncertainty and precariousness from a Sociology of Bodies/Emotions. Finally, as an open conclusion, some lines pointing at the theoretical-epistemological importance of looking at conflict as a way of approaching "risk societies" are delineated, indicating some of the ways in which habitability, environment and labour configure "precarious bodies" in XXIst Century Global South.
\end{abstract}

\section{KEY WORDS}

Uncertainty, precariousness, conflict, bodies/emotions. 


\section{INTRODUCCIÓN}

El riesgo, la incertidumbre y la precariedad intervienen activamente en la re-producción de las ciudades contemporáneas. En los albores del siglo XXI, pueden identificarse diversas formas en las que dichos rasgos se materializan en las prácticas, experiencias y emociones de las mujeres y varones que pueblan el Sur Global.

En este trabajo, el Sur Global es comprendido a partir de las re-elaboraciones planetarias de las relaciones entre imperialismo, dependencia y colonialidad (Scribano 2004). En esta clave, se acuerda con Santos (2011: 35) en la idea de que, lejos de operar como un concepto geográfico, es una metáfora del sufrimiento humano causado por el capitalismo y el colonialismo a escala global y de las resistencias para superarlo o minimizarlo. Forman parte de estas cartografías inmigrantes indocumentados, residentes de enclaves de extrema pobreza, desempleados, trabajadores esclavizados, víctimas de la violencia de género, de la trata de personas y del racismo, poblaciones desplazadas objeto de la violencia bélica, entre otros. Es un Sur apostado en los confines sociopolíticos y económicos del mundo capitalista, atravesado por la lógica extractivista que confisca la potencia y potencialidad de los cuerpos, configurando un particular escenario de sujeción y disponibilidad neo-colonial ${ }^{1}$.

Así, en la actual fase histórica del capital, el Sur Global adviene metáfora espacio-temporal de los procesos de expulsión, desposesión y expropiación a partir de los cuales acontece la violencia del despojo existencial. Las aludidas extracciones energéticas se entraman en un conjunto de sensibilidades a partir de las cuales el capitalismo se hace cuerpo, memoria y narración del mundo. De allí la relevancia teórica (pero también política) de observar dichos procesos como parte del entramado de dominación que permea las prácticas y sentires cotidianos de los sujetos, merced a una profunda (y extensa) dinámica de colonización del "planeta interno" (Melucci 2016) sobre la que opera buena parte de la expansión capitalista actual.

Desde esta perspectiva, el artículo que aquí se presenta se propone establecer algunas conexiones y discusiones en torno al riesgo, la incertidumbre y la precariedad como categorías clave para el análisis de los conflictos sociales en escenarios urbanos del Sur Global. Particularizando la mirada en procesos colectivos ligados al habitar, el ambiente y el trabajo, desde una Sociología de los Cuerpos/Emociones se busca reponer algunas de las formas en las que el riesgo y la incertidumbre moldean "cuerpos precarios".

${ }^{1}$ Según Scribano (2009) la situación actual del capitalismo neo-colonial a escala planetaria en general, y en los países del Sur Global en particular, se caracteriza por la articulación de tres ejes: a) las prácticas depredatorias de bienes comunes (agua, aire, tierra y energía); b) la producción y manejo de dispositivos de regulación de las sensaciones y mecanismos de soportabilidad social y c) las redefiniciones de la represión-militarización de las sociedades a partir de un aparato represivo disciplinar y de control que trasciende la mera ocupación militar territorializada. 
Se parte del supuesto de que es posible identificar los procesos de estructuración social a partir del análisis de los conflictos asociados a prácticas colectivas que tienen lugar en un enclave tiempo-espacio particular. Los modos de habitar, las maneras de percibir lo ambiental y las metamorfosis del mundo del trabajo constituyen tres de los principales nodos de la experiencia de los sujetos. De ahí que indagar las conflictividades que se articulan en torno a dichos ejes contribuye a comprender los procesos estructurales y el entramado de sensibilidades que pueblan las cartografías urbanas en el escenario aludido.

Así, entendiendo que las transformaciones en las formas sociales de habitar, respirar y trabajar en las ciudades abren un espacio de interrogación sobre las relaciones entre riesgo, incertidumbre y precariedad, este artículo se organiza del siguiente modo. Primero, se presenta una breve sistematización de las nociones de riesgo, incertidumbre y precariedad, recuperando los principales aportes efectuados desde las Ciencias Sociales. Sobre esta base, se plantea una aproximación teórica a los "cuerpos precarios", enfatizando la relevancia de una mirada desde la conflictividad social. Segundo, en base al análisis cualitativo de material empírico ${ }^{2}$, se sintetizan escenas conflictuales en torno al habitar, el ambiente y el trabajo que han tenido lugar en los últimos años en contextos urbanos de Argentina, estableciendo enlaces teóricos con las nociones de riesgo, incertidumbre y precariedad desde una Sociología de los Cuerpos/Emociones. Finalmente, a modo de conclusión, se abren algunas pistas que señalan la relevancia teórico-epistemológica de observar el conflicto como un modo de acercamiento a las "sociedades del riesgo", indicando ciertos sentidos en que la habitabilidad, el ambiente y el trabajo configuran marcas en los "cuerpos precarios" del Sur Global en el siglo XXI.

\section{RIESGO, INCERTIDUMBRE Y CONFLICTO SOCIAL: HACIA UNA SOCIOLOGÍA DE LOS “CUERPOS PRECARIOS”}

Uno de los rasgos cardinales de las sociedades actuales es la generalización del riesgo y la incertidumbre (Giddens 1994; Beck 1998; Bauman 2009; Luhmann 2006; Castel 2004). La crisis de la "modernidad organizada" (Wagner 1994) supuso el repliegue de las principales regulaciones estatales y mercantiles que garantizaban el acceso a seguridades mínimas para gran parte de la población. Dicha formación, que se consolida en el siglo XX, se caracteriza por la preponderancia de lo colectivo como superficie de inscripción de las más variadas zonas de la vida social: trabajo, servicios públicos, vivienda, etc. En

${ }^{2}$ Material resultante de investigaciones conducidas por las autoras y autor de este artículo, en el marco de sus respectivas carreras de investigación científica (CIC) en el CONICET. En las tres indagaciones se realizaron entrevistas en profundidad en las principales urbes del país (Buenos Aires y Córdoba). Desde sus particularidades, los resultados de estos estudios muestran las prácticas del habitar, "respirar" y trabajar en las ciudades del Sur Global como unidades de análisis relevantes para observar los modos en que se conectan conflictividades, cuerpos y emociones. 
este marco, el individuo se concibe como tal en tanto se encuentra inscripto en ese complejo conjunto de regulaciones que operan como "soportes" necesarios para que las mayorías puedan participar de los intercambios sociales (Castel y Haroche 2001). Aunque la "modernidad organizada" no es una sociedad de iguales, las distintas fracciones de clase se encuentran amparadas por el mismo sistema de protección social. En este contexto, el problema del riesgo refiere a las contingencias que las diferentes actividades sociales o económicas acarrean potencialmente sobre los individuos, al punto que la sociedad es sindicada como "responsable" de las consecuencias negativas sobre la vida del individuo, y por ello queda obligada a proteger a las personas y familias.

Frente a la crisis de la "sociedad salarial" (Castel 1997) que se inicia en los años setenta, la "protección social" es reemplazada por una lógica de tipo "aseguradora" en la que el propio sujeto es visto como el portador potencial de los riesgos y, por tanto, como responsable de sus acciones y de sus contingencias. Desde la teoría social, se diagnostica el despliegue de una "sociedad del riesgo" (Beck 1998), la cual se sustenta en la observación de la incapacidad de las sociedades para garantizar la protección de los individuos, haciendo del riesgo la condición definitoria del sujeto (Giddens 1994).

En esta línea, el riesgo es definido como una construcción socio-histórica que escapa al cálculo de probabilidades. Particularmente, para Beck y Giddens, la sociedad actual genera riesgos tecnológicos, ecológicos y sociales desconocidos hasta el momento, cuya magnitud e implacabilidad sobre la vida viene precisamente a deslegitimar las instituciones clásicas de la modernidad. Para estos autores, el riesgo es "el costo de oportunidad en la vida moderna", con efectos contradictorios: si bien "lo moderno" implica mayor seguridad respecto al orden tradicional (debido al surgimiento de los Estados Nación, la monopolización de la violencia por parte del Estado, las mejoras en las condiciones de salud de la población en general, entre otros factores) también conlleva nuevos riesgos, asociados a las posibilidades de colapso de la economía mundial, la precarización de las condiciones de vida, la potencialidad de un conflicto nuclear o de un desastre ecológico, etc. Estos riesgos, ligados a la globalización, se expanden junto a los "sistemas expertos" que organizan los grandes ámbitos de la vida material y social, cuyas capacidades abstractas los sujetos tienden a establecer como "fiables". Desde estas miradas sociológicas, el riesgo es constitutivo de la sociedad y del individuo. Es una configuración socio-histórica que adquiere la experiencia individual para enfrentar lo indeterminado del mundo, de allí que sea asumido como un principio ordenador de lo social, en tanto posibilita racionalizar reflexivamente lo contingente (Beck, Giddens y Lash 1997)

Para Beck (1998), la intensa división social del trabajo que caracteriza a las sociedades posmodernas diluye las responsabilidades sobre los riesgos, al punto de que cada eventual responsable puede delegar su culpa en otras partes interdependientes del todo. Desde esta perspectiva, la omnipresencia del riesgo homologaría las diferencias de clase, tanto en materia de responsabilidad como de exposición a los diferentes tipos de riesgos. 
En oposición con esta mirada, Castel sostiene que en las sociedades actuales la exposición al riesgo es desigual, como también son desiguales los recursos que dispone cada individuo para protegerse. Tomando distancia de la "inflación" de la noción de riesgo -a partir de la cual los miedos afloran por doquier- que ha llevado a sentar las bases diagnósticas para una "sociedad del riesgo" (Beck 1998) y una "cultura del riesgo" (Giddens 1994), Castel sostiene una concepción diferencialista de los riesgos y de las políticas para combatirlos. Postula la necesidad de distinguir y caracterizar cada riesgo de acuerdo a su especificidad, así como definir los modos más adecuados para afrontarlos. "Por ejemplo, la desocupación es hoy un riesgo en el mundo del trabajo, así como el calentamiento del planeta es un riesgo que amenaza con destruir los equilibrios ecológicos. Pero se ve bien que la desocupación y el calentamiento global no se combaten con los mismos medios" (Castel 2013: 33). De acuerdo con este autor, el riesgo es una construcción colectiva que surge en referencia a la actuación del Estado $\mathrm{y}$ de sus instituciones.

A diferencia de Beck y Giddens, para Castel el riesgo no es una condición inherente al sujeto ni tampoco un elemento intrínseco a la "modernidad tardía", sino más bien una configuración histórica (relativa) que surge en referencia al sistema de protección que normativamente genera una sociedad en un periodo dado (Castel 2004). Según este sociólogo francés, es menester deconstruir las concepciones globalizantes del riesgo, deshaciendo la amalgama que frecuentemente opera entre diversos tipos de ellos (desde el desempleo a una enfermedad, pasando por un ataque informático, el endeudamiento o el cambio climático). Tal entrelazamiento y confusión de riesgos "lleva a adicionar el conjunto de los miedos que esos distintos tipos de riesgos suscitan. El resultado es una pintura de la sociedad en la cual estamos sitiados desde todas partes por toda clase de riesgos, sumergidos por los riesgos, y en consecuencia reducidos a la impotencia frente a ellos" (Castel 2013: 40) ).

Junto al riesgo y la incertidumbre, la problematización de la precariedad ha ganado espacio en las discusiones de las Ciencias Sociales durante las últimas décadas. La etimología moderna del término refiere "aquello cuya duración y solidez no está asegurada, sino que se halla unido a lo inestable e incierto, a aquello que es corto, fugaz o fugitivo, así como a lo que es delicado y frágil" (Cingolani 2014: 49). Teniendo en cuenta la reconfiguración del lugar del trabajo en los procesos de "desmoronamiento" de la "sociedad salarial", no sorprende que muchas de las lecturas existentes acerca de la precariedad/precarización se estructuren en función de las tensiones entre la disminución de la calidad de las condiciones de trabajo y de la calidad de vida en las sociedades en "metamorfosis" (Castel 1997).

En esta dirección, Castel (2007) refiere a le precariat como un "no empleo" de masas, es decir, la institucionalización de una situación global de deterioro de la norma de empleo, al tiempo que Appay y Jefferys (2009) vinculan la precarización no ya a los procesos periféricos, sino a la institucionalización de la inestabilidad económica y social en contextos de transformaciones regresivas del trabajo y la protección social. 
Por su parte, Butler (2006) y Lorey (2008) abordan la precariedad como un instrumento central de las sociedades capitalistas, en las que el dominio no se legitima por la seguridad sino por la inseguridad económica, social, política y subjetiva. Ambas autoras subrayan la importancia de una discusión teórico-política que reponga la condición precaria de la vida humana que, como tal, requiere protección social, política y económica.

Butler distingue entre precarity (precaridad) y precariousness (precariedad). El primer término refiere a la ontología de la vida -caracterizada por la finitud y vulnerabilidad del cuerpo, así como por la dependencia respecto de otros- por lo que la protección deviene un imperativo para la afirmación vital. El segundo concepto, señala que la subsistencia está amarrada a la satisfacción de un conjunto de necesidades económicas, políticas, jurídicas y sociales, de manera que aquellos sujetos que no consigan "cubrirlas" quedan inmersos en una condición de precariedad, estrechamente asociada con la desigualdad social en un momento histórico dado. Esta elaboración permite a la autora postular la existencia de una distribución diferencial de la vulnerabilidad en el capitalismo e, incluso, operaciones de exclusión acerca del acceso a la inteligibilidad de unas vidas por sobre otras, lo que conduce a que ciertas poblaciones se hallen mayormente expuestas a la violencia. En sintonía con esta mirada, Lorey (2008) propone la categoría precarización de sí, para dar cuenta de la normalización de los procesos de precarización en escenarios neoliberales, en los que se gobierna mediante la inseguridad económica, laboral y vital. Consecuentemente, desde la visión de estas autoras, la precariedad no puede homologarse a un aspecto de la vida (inseguridad laboral, falta de cobertura social, etc.), sino que responde a una condición de la existencia y de la subjetivación.

También cobran relevancia las observaciones sobre la idea de precariedad efectuadas por Dörre (2009). Este autor señala que los escritos sobre la acumulación originaria de capital en Marx constituyen un temprano análisis de la relación entre capitalismo y colonización, en tanto se ocupan de la emergencia de un modo de producción capitalista en un contexto no capitalista. Esta noción de colonización puede asociarse a formas históricas o a procesos actuales. También expresa la idea de que pueden colonizarse áreas dentro de la sociedad capitalista, o crear activa e infinitamente el "afuera" (Harvey 2004). Desde esta perspectiva, la precariedad es una de las formas posibles de recrear interminablemente el "afuera" y, por tanto, la misma tiende a un infinito progresivo, ligado a la dinámica de la expansión capitalista. Así, riesgo, incertidumbre y precariedad no sólo resultan dimensiones centrales de la configuración histórica de un proceso globalizante de re-estructuración social sino que, al mismo tiempo, constituyen rasgos relevantes de las experiencias geopolíticamente situadas.

Es precisamente acentuando la mirada sobre esta lógica en los territorios neo-coloniales que este artículo busca recuperar la potencialidad de una Sociología de los Cuerpos/Emociones como clave de entrada analítica a los millones 
de "cuerpos precarios" que transitan los procesos de habitar, respirar y trabajar en el Sur-Global'.

Asumiendo la complejidad de las relaciones globales-locales que configuran el aludido "desmoronamiento" de la "sociedad salarial", es necesario destacar que los procesos de re-configuración de la calidad de vida de las personas en los territorios que aquí se analizan no se produjeron (ni se producen) en un marco de "tolerancia social". Por el contrario, la conflictividad social constituye un rasgo central de los procesos de estructuración, por lo que resulta indispensable desarrollar una "hermenéutica del conflicto" que permita recuperar, desde la perspectiva de los actores, aquellos mensajes que la sociedad comunica sobre sus procesos de re-producción (Melucci 1996).

En este sentido, una de las preguntas centrales es cómo los conflictos se han estructurado en función del cuerpo y las emociones. Lo primero, en tanto el cuerpo deviene no sólo objeto de explotación-expropiación sino también territorio donde se dirime el conflicto. La expansión colonial sobre el "planeta interno" parece marcar el horizonte expansivo del capital y, en este sentido, sobre las emociones se monta una serie de mecanismos y dispositivos orientados a performar los modos de sentir, ocluyendo los conflictos, y consagrando la mercantilización de la vida como la "forma natural de vivir" (Melucci 2016; Scribano 2009).

Así, el "cuerpo precario"4 remite a la geo-inscripción de millones de sujetos que se ubican en posiciones vecinas, configuradas a partir de las coordenadas que arrojan los saldos negativos de los procesos expropiatorios en los confines neo-coloniales del capital. Se trata de cuerpos marcados por la falta de acceso a los nutrientes, enfermos por los procesos de contaminación, estresados por las exigencias laborales y sociales a que se encuentran sometidos. Cuerpos signados por la falta de referentes identitarios ante la pérdida de centralidad de la ocupación como organizador de un sistema de status; marcados por frágiles construcciones de pertenencia a territorios socio-segregados, o directamente negados/ silenciados debido a las expulsiones productivas generadas por la expansión de los geo-circuitos del extractivismo. Cuerpos que encarnan mandatos de "lo productivo", así como de "lo deseable", en torno a cómo y dónde vivir, derivados de los mecanismos metabólicos a partir de los cuales las energías vitales devienen capital acumulable.

${ }^{3} \mathrm{El}$ análisis que aquí se presenta se inscribe en un posicionamiento teórico que parte de reconocer la relación insoslayable que existe entre la corporalidad y la emocionalidad para la comprensión de los procesos de estructuración social en el marco de las sociedades capitalistas. En tal sentido, se asume que sentirse en cuerpo/un cuerpo remite a un plano cognitivo-afectivo que ponen en juego los sujetos para vivenciar(se) en el marco de la materialidad que suponen (e imponen) las experiencias encarnadas de lo social. Cfr. Scribano 2013; Cervio 2012; Scribano y Lisdero 2010.

${ }^{4}$ Desde una perspectiva diferente, Butler (2006) define el concepto "vidas precarias" para aludir, en simultáneo, a la condición de precariedad de la vida y a la diferenciación social establecida mediante la cual determinadas vidas no son inteligibles y, por tanto, perderlas no implicaría la necesidad de elaborar un duelo. En el marco de este escrito, el "cuerpo precario" es un concepto emergente de diversas investigaciones empíricas situadas. Una definición próxima a la que aquí se propone puede encontrarse en: Lisdero 2009; Cervio 2010; D'hers 2013. 
En esta línea, el "cuerpo precario" remite a una geometría social inscripta en procesos globales de expansión del capitalismo, asociada a una particular gramática de acción. Las externalidades de los procesos de desarrollo constituyen marcas en los cuerpos, las cuales portan ciertas inercias sociales orientadas obstaculizar el auto-hetero-reconocimiento, promoviendo así la minusvalía de la acción.

\section{3. “CUERPOS PRECARIOS” Y CONFLICTIVIDAD SOCIAL}

Con el objetivo de analizar los modos en que el riesgo y la incertidumbre moldean a estos "cuerpos precarios", en este apartado se sintetizan algunas escenas conflictuales en torno al habitar, el ambiente y el trabajo que han tenido lugar recientemente en contextos urbanos argentinos.

\subsection{Habitar}

En Argentina, desde hace (mucho) más de medio siglo, las villas y asentamientos informales constituyen los reservorios de la pobreza más extrema. Aunque no agotan todas las formas de precariedad habitacional registrada a escala urbana -aquí deben agregarse también los inquilinatos, hoteles, pensiones y casas tomadas- su impacto social, económico, ambiental y estético sobre la vida de las ciudades es innegable.

Las villas son urbanizaciones asentadas en tierras de propiedad fiscal o de terceros. Poseen una trama irregular, con acceso a las viviendas a través de pasillos, y el proceso de ocupación suele ser individual. Por su parte, los asentamientos informales son resultantes de la ocupación colectiva de tierras, en su mayoría, privadas. Poseen un trazado regular y planificado. Las familias autoproducen de distintas maneras las infraestructuras y viviendas, generalmente observando las normas vigentes, en tanto existe la perspectiva de regularización a través de la intervención estatal (Varela y Cravino 2008).

Según el último dato disponible, en 2017 existían en el país 4228 villas y asentamientos informales habitados por unos 3.5 millones de personas ${ }^{5}$. En su conjunto, ocupan más de $330 \mathrm{~km}^{2}$, es decir, un área más extensa que la Ciudad de Buenos Aires. Más de la mitad de estas urbanizaciones se formaron antes del año 2000, mientras que casi un cuarto surgió con posterioridad al 2010. El 56\% de los residentes registrados por el estudio eran niños y jóvenes de hasta 24 años. El 24\% de los mayores de 16 años no trabajaba, el $21 \%$ poseía un trabajo en el mercado informal y sólo el $16 \%$ tenía un empleo en "blanco". Por su parte, otra fuente (ODSA 2017) señala que casi 8 de cada 10 hogares pobres localizados en

${ }^{5}$ Relevamiento nacional implementado por el Poder Ejecutivo Nacional. Disponible en: https://zuletasintecho.files.wordpress.com/2018/04/resumen-informe-de-gestic3b3n-renabapac3b1o-2017-docx.pdf 
villas y asentamientos de Argentina perciben alguna transferencia mensual de ingresos por parte del Estado (77.9\%) que les posibilita acceder al mercado de bienes para satisfacer necesidades básicas.

Así, en condiciones de pobreza y de alta dependencia de la asistencia estatal, la incertidumbre y la precariedad advienen rasgos estructurales sobre los que se monta buena parte de la vida cotidiana. La falta de agua potable, cloacas, educación, trabajo y salud son, entre otras, las condicionalidades bajo las cuales se reproduce la vida de millones de argentinos, por lo cual se comprende que los riesgos asociados no son una condición "inherente" al sujeto (Beck 1998) sino más bien un "rasgo estructural" (que se hace cuerpo/emoción ${ }^{6}$ ) resultante de las crisis de los sistemas de protección social y del mercado de trabajo que se suceden -con sus reconfiguraciones- desde los años 70 del siglo XX (Castel 1997).

Si se asume que las políticas de las sensibilidades son "el conjunto de prácticas sociales cognitivo-afectivas tendientes a la producción, gestión y reproducción de horizontes de acción, disposición y cognición" (Scribano 2017: 244), ¿cuáles son y cómo operan las "sensibilidades del riesgo" en escenarios urbanos de extrema pobreza?; ¿cuáles son las estrategias individuales y colectivas para el manejo de la incertidumbre que se elaboran en enclaves urbanos altamente precarios?; ¿qué sentidos reviste la precariedad para cuerpos que han naturalizado dicha condición como un rasgo (invariante) de sus experiencias del habitar?

La exploración de esta problemática entre habitantes de barrios precarios muestra la convergencia de distintos procesos estructurales, con evidentes impactos en el plano de las experiencias y emociones. Procesos que, dada su complejidad inherente, posibilitan observar las conexiones entre precariedadriesgo-incertidumbre en clave de un habitar que se despliega y reconfigura desde la lógica de la "intemperie".

Según el Diccionario de la Lengua Española, quedar a la intemperie es estar "a cielo descubierto, sin techo ni otro reparo alguno" (RAE 2018). De la acepción anterior puede derivarse que es estar ex -puesto a los riesgos que supone no tener "lo mínimo que hay que tener" para el desarrollo adecuado de la vida. Es estar por fuera del cobijo que otorgan las protecciones sociales como derechos. Es quedar desamparado en el marco de una sociedad que ha privatizado los riesgos, responsabilizando cada vez más a los sujetos por la gestión de sí.

En el corpus empírico construido en base a entrevistas en profundidad ${ }^{7}$, las

${ }^{6}$ Se alude a las "políticas de los cuerpos /emociones" que elabora y sobre las que se funda la expansión capitalista. Éstas son entendidas como "las estrategias que una sociedad acepta para dar respuesta a la disponibilidad social de los individuos [convirtiéndose en] un capítulo, y no el menor, de la estructuración del poder. Dichas estrategias se anudan y 'fortalecen' por las políticas de las emociones tendientes a regular la construcción de la sensibilidad social" (Scribano 2009:146).

${ }^{7} \mathrm{El}$ material que se analiza en este apartado es resultado del proyecto "De la 'ciudad democrática' a las 'ciudades-barrios'. Sensibilidades y experiencias del habitar en la ciudad de Córdoba durante los años '80 y '2000" (CIC- CONICET, 2014-2018), investigadora responsable: Ana Lucía Cervio. En el mismo se entrevistó a residentes de barrios precarizados de Córdoba, con el objetivo de indagar experiencias del habitar y sensibilidades asociadas con procesos de organización colectiva. 
lógicas de la exposición, la expulsión y el desamparo que configuran la "intemperie" como rasgo de habitabilidad, aparecen de diversos modos, adquieren distintas fuerzas explicativas y orientan la construcción de variadas significaciones por parte de los habitantes de villas y asentamientos informales consultados. Sin embargo, por estrictas razones de espacio, a continuación se reproduce el extracto de una entrevista realizada en la ciudad de Córdoba que evidencia, sin rodeos, los riesgos e incertidumbres vinculados con un habitar precario:

C: Una vez nos agarra una epidemia de fiebre tifoidea (...) Y empezaron unas sobrinas a vomitar por boca parásitos, unos parásitos enormes, larguísimos, y otra sobrina, por vagina, unos chiquititos. Entonces yo, ni lerda ni perezosa, junté en una botella con alcohol y me lo llevé a lo que era la dependencia de dispensarios municipales. Y allí me mandaron al hospital. Me contacté con una jefa del servicio de epidemiología y pude lograr que se viniera [al barrio] una médica. Ya ella me había dicho qué tipo de parásitos eran, así que vinieron a hacer una campaña. (...) Estaba hablando la médica de lo nocivo que eran estos bichos, que había gente que podía hacer años que los tenían pero que jamás se habían dado cuenta de lo que podían llegar a ocasionar (...) Ahí, cuando analizaron el agua, supimos que estábamos con... Claro, si todos teníamos los baños a menos de dos o tres metros (...) Estaba contaminada el agua, las napas de agua estaban muy contaminadas. Y una señora dice: "Ah, yo quiero decir una cosa" (...) Me acuerdo que dijo: "yo tengo 42 años; desde que mi abuela vivía nosotros tenemos esos bichitos". Y a mí me quedó tan grabado porque ese bichito puede matar. Te puede matar, te puede perforar el intestino, te puede hacer una septicemia que no te salvás... o tenés que tener mucha suerte, por lo menos (Mujer, 59 años, Parque Liceo III).

El relato muestra con crudeza la coexistencia de, al menos, tres dinámicas. En primer lugar, la expansión de una sociedad que privatiza los riesgos e incertidumbres y que provoca, entre otros aspectos, la emergencia y sostenimiento de prácticas cotidianas de cuidado de sí y de otros (familiares, amigos, vecinos). En espacios de extrema pobreza, tales prácticas son percibidas y valoradas como una de las "únicas" opciones disponibles para asegurar la reproducción material de la vida de propios y allegados. En el marco del funcionamiento de esta dinámica autogestionaria de los riesgos y cuidados, la entrevistada narra (en detalle) las acciones personales realizadas para "lograr" la intervención del Estado sobre la problemática sanitaria identificada: juntó una muestra de agua en una botella, le puso alcohol para conservarla, la llevó al hospital, se contactó con una epidemióloga, consiguió realizar reuniones informativas y una campaña preventiva de la fiebre tifoidea en el barrio.

Ahora bien, son precisamente estas acciones individuales las que traslucen la naturaleza e intensidad de los riesgos a los que están expuestos los integrantes de la comunidad en forma sostenida, desde hace varios años. Esto se conecta con una segunda dinámica operante, ligada al acostumbramiento y naturalización de las privaciones materiales (y de los riesgos a ellas asociados) como signo de/ para la reproducción de la vida (D'hers 2013). Tener en el cuerpo esos "bichitos" desde hace al menos dos generaciones, sin que ello provoque ninguna proble- 
matización, ilustra cómo la persistencia de las faltas (agua potable y controles sanitarios, en este caso) se hace cuerpo/emoción remitiendo, con ello, a un plano cognitivo-afectivo puesto en juego por los sujetos a la hora de vivenciar(se) en el marco de la materialidad que suponen e imponen las experiencias encarnadas de lo social. En suma, el relato anterior muestra cómo para estos "cuerpos precarios" el agua y la salud que NO tienen es justamente el único tipo de agua y salud que pueden llegar a tener. Y eso es, evidentemente, una cuestión que compromete al cuerpo y a las emociones de ayer, hoy y mañana.

En tercer lugar, en un escenario que impone la autogestión de los riesgos y el cuidado como lógica reguladora de la reproducción vital, la apelación a la suerte personal parece advenir como la (última) opción (¿disponible?) para neutralizar los riesgos que supone la iteración de las privaciones con las que se vive y convive. En términos específicos, cuando la entrevistada recuerda "ese bichito que puede matar" (en alusión a microorganismos detectados en los cuerpos, como resultado de la contaminación de las napas freáticas en el barrio), pone en evidencia un factor de riesgo concreto que pesa sobre la vida de todos. Éste sólo puede ser "contenido" mediante claras políticas públicas que reviertan el escenario de des-atención crónica que impregna en estos enclaves de pobreza. Sin embargo, es la propia historia de resignaciones, convertida en vivencia del mundo, lo que conduce a esta mujer a recurrir a un proceso extra-social (fortuito y azaroso) para explicar las probabilidades de vida-muerte en las que se dirime la existencia personal en estos barrios. En otros términos: frente a la exposición continuada (inter-generacional) a los diversos riesgos que se derivan de la pobreza y la desigualdad, pareciera que sólo queda encomendarse a la "buena suerte". Y esto es, claramente, una política de los cuerpos/emociones operando a nivel individual.

\subsection{Respirar}

En conexión directa con el apartado anterior, a continuación se analizan brevemente los procesos de configuración de las "sensibilidades de la contaminación" (e incluso, de la certeza de la contaminación), observados a partir del estudio de experiencias de habitabilidad precaria en asentamientos informales de la Ciudad de Buenos Aires y el Conurbano bonaerense ${ }^{8}$.

Retomando la falta (iterativa) de los servicios e infraestructuras urbanas que caracteriza a las villas y asentamientos informales, aquí interesa dar cuenta cómo operan los mecanismos de acostumbramiento y resignación en los entrevistados, en tanto sujetos inscriptos en experiencias de contaminación "normalizadas" social e individualmente.

${ }^{8}$ El material es producto del trabajo de campo realizado en el proyecto "Construcción de las sensibilidades, percepción y política de los cuerpos. Análisis e interpretación desde la sensibilidad/expresividad" (CIC- CONICET), investigadora responsable: Victoria D'hers. Se realizaron entrevistas en profundidad en dos partidos del conurbano bonaerense (Quilmes y Avellaneda) y en Villa 31 de la Ciudad de Buenos Aires. 
En el marco de la "sociedad de riesgo" (Beck 1998), la tensión entre una mayor seguridad y orden institucional (que supone previsibilidad) y la precarización generalizada de las condiciones de vida se traduce en sensibilidades hechas "callo", es decir, sujetos acostumbrados al sufrimiento y a la necesidad como categorías que los definen en sus trayectorias vitales.

Un aspecto interesante deriva de los "sistemas expertos" (Giddens 1994) que operan en el sector (presumiblemente) controlando los riesgos, (pero) que en reiteradas oportunidades han mostrado debilidades, acentuando aún más las tensiones entre seguridad-orden-precarización antes referidas. Por ejemplo, en la Cuenca Matanza-Riachuelo el Estado es quien cuantifica, analiza y estudia los casos de contaminación, y ha confirmado la presencia de plomo, entre otros metales pesados. Sin embargo, décadas después, es el mismo organismo estatal $(\mathrm{ACUMAR})^{9}$ el que demuestra su incapacidad de resolución frente a situaciones que persisten en el tiempo, haciendo que el sufrimiento ambiental se reproduzca de generación en generación.

Es así como es posible dar cuenta de datos objetivos que muestran las problemáticas ambientales y los riesgos para la salud identificados en el sector. Por citar un ejemplo, la contaminación es un problema "asumido" en la mencionada Cuenca, así lo indica el informe 2010 de la Fundación Ambiente y Recursos Naturales (FARN):

Según estudios citados por el INADI en su Recomendación 7/2009, un mejor saneamiento del medio permitiría evitar un $41 \%$ de las muertes por infecciones de las vías respiratorias inferiores y $94 \%$ de las muertes por enfermedades diarreicas en el mundo. La realización de la Encuesta de Factores Ambientales de Riesgo para la Salud, ordenada por el fallo de la Corte, dio cuenta de que el 96,4\% de la población de la CMR se encuentra expuesta a -al menos- una amenaza de riesgo ambiental. Las mismas se han establecido en función de las características de los lugares de residencia de los habitantes de la cuenca, destacándose la carencia de servicios públicos básicos y la cercanía a fuentes puntuales de polución (FARN 2010: 65).

Un caso emblemático de esta problemática es Villa Inflamable, localizada en Dock Sud (Avellaneda, Buenos Aires). Hace décadas que oficialmente se ha establecido la necesidad de trasladar a un número de familias residentes, altamente expuestas a la contaminación ambiental por hidrocarburos, específicamente. El Estado ha afirmado en numerosos informes el riesgo ambiental y social bajo el cual se encuentran las más de 1500 familias asentadas en las inmediaciones del Polo Petroquímico de Dock Sud. ${ }^{10}$ Concretamente, se ha demostrado que la presencia de contaminantes en sangre impide el correcto desarrollo del sistema nervioso central y, por tanto, cualquier otra búsqueda de igualdad en el futuro ${ }^{11}$.

\footnotetext{
${ }^{9}$ Autoridad de la Cuenca Matanza-Riachuelo.

10 Véase: https://www.lanacion.com.ar/1699306-una-batalla-diaria-contra-los-efectos-de-lacontaminacion

${ }^{11}$ Sólo a modo de ejemplo de cómo el tema persiste y los avances son casi nulos, veáse: https://www.lanacion.com.ar/2110278-riachuelo-contaminacion-ambiental-y-riesgo-para-la-salud.
} 
Frente a esto, es posible recuperar experiencias acerca de las afectaciones corporales de la contaminación, en las que el relato se posiciona como "resistencia" frente a la intemperie en la que se vive, y también como visión hacia el futuro:

Y bueno, le digo a mi marido vámonos, qué vamos a estar rogando tanto. Y él dijo, "no, si la gente viene y se manda por qué yo no puedo tener". No sé qué se le cruzó por la mente a mi marido, caminó ese día, caminando dando la vuelta por ahí, en un lugar con piedras enorme, y se bajó ahí. Estuvimos casi en un mes, ahí viviendo, bajo una bolsa de plástico que hizo con unos cosos de madera. Y dormíamos ahí, cuando llovía nos tapábamos con la bolsa, y trajo una cama de plaza y media mi marido. Y nos quedamos ahí. De a poco fue levantando la casa de madera y cartón, un cuartito (...) Ni los delincuentes me parece que viven así, nosotros estamos más en la cárcel que en otro lado. (...) me imaginé el movimiento de la gente en la ciudad, todo eso. Y esa impotencia que uno siente... (Mujer, 46 años, Villa 31, Buenos Aires).

Yo me imagino. Esta gente está acostumbrada a vivir así... Yo conozco una persona que vive al costado del Riachuelo hace 50 años. Y en 50 años te acostumbras a respirar así. Yo no quiero 50 años para mis hijos que vivan así. (Mujer, 32 años, Barrio en Lomas de Zamora).

No tenemos servicios, pero me gusta el campo... Exagera el municipio con que todo está contaminado, lo quieren vender a XX [nombre de una empresa privada] (Varón, 50 años, Villa Inflamable).

¿Acá? Donde vayas hay contaminación. Si cambiara me quedaría por acá, no me gustan los sitios cerrados (Varón, 25 años, Villa Inflamable).

Acá te bañás y te pica todo el cuerpo... Es lo que nos toca. (Mujer, 51, Villa Inflamable).

Entrevistadora: ¿Tenés enfermedades actualmente?

Mi hija, plomo en la sangre tiene, desde los 4 años... Será que nos sacan algún día? Yo quiero salir pero que me den una vivienda, los departamentos son chicos (Mujer, 44 años, Villa Inflamable). ${ }^{12}$

Estos breves extractos sintetizan, además de la situación de precariedad ambiental referida más arriba, el entrecruzamiento del acostumbramiento y la naturalización de lo que hay que hacer para llegar a vivir en estos barrios y (literalmente) salir de la intemperie. Asimismo, muestran el solapamiento de la contaminación con problemáticas de salud que profundizan aún más la precarización habitacional y ambiental reinante.

En este marco, y retomando el imperativo teórico-político de reponer la discusión sobre la precariedad (precariousness) en tanto condición de la vida de millones de sujetos que pueblan en el Sur Global (Butler 2006; Lorey 2008), puede observarse con claridad cómo estos "cuerpos de la contaminación" constituyen la prueba más radical de la violencia y el riesgo. Y esta tensión entre

${ }^{12}$ Excedería el alcance de estas páginas delinear la problemática ambiental en cruce con las promesas y tensiones ligadas a las "relocalizaciones", tanto de la población de Villa Inflamable, como de quienes ocupan el llamado Camino de Sirga; tema central de la actual gestión de ACUMAR. Cabe destacar que se viene anunciando la mudanza de los vecinos desde el año 2006. A la fecha sólo fueron relocalizados algunos, en situaciones atravesadas por diversas conflictividades. 
violencia y riesgo estructural se manifiesta, al menos, en un doble sentido: los sujetos no sólo encarnan (hacen cuerpo) el sufrimiento sino que saben de él; tienen la "certeza", paradójicamente, de que habitan y con-viven en un espacio altamente contaminado. También saben que el Estado posee dicho conocimiento y, aún así, no funge como protector de sus derechos (más) básicos.

En línea con lo planteado por Lorey (2008), la precariedad funciona en tanto condición de subjetivación dentro de las técnicas de normalización de los gobiernos neoliberales, a la vez que opera como acostumbramiento, constituyendo un limitante concreto para las posibilidades futuras.

Continuando con la pregunta abierta previamente sobre cómo son y cómo operan las "sensibilidades del riesgo" en escenarios (presentes y futuros) y cuáles son las estrategias del manejo de la incertidumbre, la cuestión del tiempo deviene clave. Si en algún sentido la incertidumbre se conecta con la inseguridad, ésta debe tensionarse con un fenómeno concreto que se repite en estas cartografías de la precariedad: la "seguridad de no poder" en el futuro, es decir, de no disponer de las energías corporales y sociales necesarias para participar (poner el cuerpo) en acciones colectivas que busquen revertir este escenario de profunda desigualdad.

Redoblando la apuesta analítica relacionada con estos interrogantes, ¿qué sentidos reviste la precariedad para cuerpos que han naturalizado dicha condición como un rasgo (invariante) de sus experiencias del habitar desde hace varias generaciones? Sin dudas una posible (y muy provisoria) respuesta se complejiza al reflexionar no sólo en torno al habitar en condiciones de precariedad sino de llevar la contaminación en el propio cuerpo, con todas las implicancias fisiológicas, subjetivas y sociales que conlleva el convertirse (y saberse) un "cuerpo de la contaminación".

\subsection{Trabajar}

$\mathrm{Al}$ caracterizar la precariedad en los ámbitos del trabajo, diversos especialistas advierten que ésta puede resultar un concepto ambiguo y multifacético (OIT, 2012). Sin embargo, el trabajo precario se asocia con la lógica del riesgo y la incertidumbre como rasgos comunes sobresalientes:

(...) trabajo precario es un medio utilizado por los empleadores para trasladar los riesgos y las responsabilidades a los trabajadores. Es el trabajo que se realiza en la economía formal e informal y que se caracteriza por niveles variables y grados de particularidades objetivas (situación legal) y subjetivas (sensación) de incertidumbre e inseguridad. Si bien un trabajo precario puede tener diversas facetas, se lo suele definir por la incertidumbre que acarrea en cuanto a la duración del empleo, la presencia de varios posibles empleadores, una relación de trabajo encubierta o ambigua, la imposibilidad de gozar de la protección social y los beneficios que por lo general se asocian con el empleo, un salario bajo y obstáculos considerables tanto legales como prácticos para afiliarse a un sindicato y negociar colectivamente. (OIT 2012: 32) 
Contra la imagen de la estabilidad asociada al trabajo, el comienzo de este nuevo milenio parece imponer una postal diferente: según informes de la OIT, la tasa de desempleo mundial para 2017 se situó en 5,6\%, con un número total de desempleados superior a 192 millones. Se estima que el $42 \%$ de los trabajadores en el mundo (esto es, 1400 millones de personas) se encuentra en modalidades de empleo vulnerable ${ }^{13}$, en tanto que los ingresos o el consumo per cápita de más de 300 millones de trabajadores (9\%) es inferior a 1,90 USD (pobreza laboral extrema), y de entre 1,90 y 3,10 USD (pobreza laboral moderada) para 430 trabajadores (13\%). (OIT 2018). En Argentina, de las 18 millones de personas ocupadas, poco más de la mitad constituyen asalariados registrados, en tanto el resto son trabajadores en relación de dependencia no protegidos (condiciones precarias de contratación) y trabajadores no asalariados (la mayoría sin registrar). (Lindenboim 2018).

Así, de manera creciente, el trabajo, como aquella actividad que ocupaba buena parte de la vida de la población global -y que sobre todo brindaba las coordenadas para la estructuración de una identidad estable- comienza a "desmoronarse", y con ello, el conjunto de beneficios y prerrogativas que configuraban las condiciones materiales de dicha "estabilidad". Es en este contexto que los riesgos de "quedar desempleado", o de caer en las múltiples e iterativas actividades comerciales y de servicios necesarias para "poner a andar" las megaconcentraciones urbanas, constituyen un "rasgo estructural" asociado a la desestabilización que vivencian los trabajadores para planificar sus vidas, a malas condiciones de salud, a las desigualdades por género en las situaciones laborales, a la disuasión de participación en sindicatos o en general en procesos de cooperación societales (OIT 2012).

La "sensación de impotencia y temor" (OIT 2012: 46) ocupa un lugar central en este fenómeno, lo cual re-conduce a la pregunta por la política de las sensibilidades: ¿cómo operan estas sensaciones en la experiencia cotidiana de trabajadores precarios?; ¿cuáles son los mecanismos a partir de los cuales la incertidumbre se imprime como un organizador de la vida y qué consecuencias tiene para la estructuración de los conflictos laborales?; ¿qué implica la vivencia de un cuerpo precario dispuesto en estas posiciones y condiciones de trabajo?

$\mathrm{Al}$ poner estos interrogantes en el horizonte de la experiencia de trabajadores precarios ${ }^{14}$ surgen algunas claves de lecturas asociadas a la lógica de la intempe-

${ }^{13}$ Sin bien para definir el empleo vulnerable se toma en consideración a los trabajadores familiares no remunerados y los trabajadores por cuenta propia, éste se considera un indicador para aproximarse a ciertos fenómenos incluidos dentro de lo aquí interesa como precariedad laboral (OIT 2018).

${ }^{14}$ En este sub-apartado se presentan fragmentos de entrevistas realizadas en Córdoba entre 2007 y la actualidad, en el marco de diferentes proyectos de investigación, todos ellos enmarcados en la línea de indagación que Pedro Lisdero viene desarrollando como investigador de CONICET (proyecto actual: Acción colectiva, sensibilidades y trabajo. Conflictividades emergentes y procesos expropiatorios en el contexto de las nuevas morfologías del trabajo (2016-2019). Las investigaciones desarrolladas abordan la problemática del cuerpo como bien y locus del conflicto en el contexto de conflictos laborales emergentes. 
rie aludida, tales como la exposición a los riegos del trabajo precario, la expulsión del ámbito de las certezas que otrora otorgaba el status de "ser empleado", y el desamparo asociado con la fragmentación de las solidaridades colectivas y con la re-asignación de las responsabilidades individuales sobre los cuidados laborales.

Así, caer en la zona de la "alta rotatividad" que implica transitar los diferentes trabajos precarios, supone adentrarse en una especie de laberinto para la experiencia, donde las habilidades necesarias para sortear los obstáculos de la vida laboral se estructuran en función de "acostumbrarse a estar permanentemente en busca de trabajo":

E: Antes de entrar a trabajar en el Call Center, qué hacías?

N: Yo ya había trabajado antes. En Córdoba estaba vendiendo seguros de casas, así, en los bares. Y también trabajé en un par de pizzerías (...)

E: y de ahí cómo es que pasaste a los calls?

$\mathrm{N}$ : Y lo que pasa es que [el call center] era lo nuevo (...): (lo positivo era) el sueldo y la carga horaria. Si hacés la cuenta, vos en una pizzería estás trabajando 8 horas, de lunes a lunes, que es una locura y en negro ¿entendés? A laburar ahí que eran 6 horas, de lunes a viernes. (Varón, 29 años, Trabajador de Call Center).

Las múltiples "ocupaciones" que caracterizan la circulación de los sujetos se articulan armoniosamente desde la experiencia de un "cuerpo precario" que asume como un "cálculo personal" aquellos costos derivados de la re-asignación de las energías productivas. Los horizontes de lo deseable, de "lo nuevo", se asocian a la naturalización de ciertas condiciones (tener que moverse permanentemente de trabajo) las que, a su vez, se imprimen como "marcas identitarias" en los propios cuerpos (ser alguien que se amolda a nuevos trabajos). Así, cuando el "ropaje" de la fantasía de que "éste es el mejor trabajo" se cae, emerge crudamente la precariedad que implica a un cuerpo como reservorio energético ("sangre joven") dispuesto a ser procesada ("picadora de carne"):

Saben que le están mintiendo a la sociedad de Córdoba, diciendo que es una escuela de trabajo... Es una picadora de carne: eso es lo que son los Call Center en Córdoba hoy (...) somos la sangre joven... [sabemos que] en cinco años tenemos un problema social en Córdoba, porque cuando salgas del Call no vas a poder entrar en otro trabajo, porque no te van a dar los oídos, la garganta. (Varón, 45 años, Trabajador de Call Center).

En este contexto, la expansión de la precariedad, ligada a la fragilidad sistemática del empleo y la marginalización de parte importante de la población, caracteriza el escenario social donde la "inseguridad" resulta "endémica" (Beck 2000: 12). Sin embargo, se aprecia que las sociedades del Sur Global presentan ciertas proximidades de clase entre quienes tienen cierta disposición a vivir esta "inseguridad" en forma de "amenaza" e "impotencia": 
Empezaron con unos rumores de que iba a cerrar el Call... Los rumores de que se cierran los Call son siempre, siempre los mismos. O sea [en otro call center] también tuvimos ese rumor, de que iba a cerrar y demás. Siempre hay rumores. (Mujer, 25 años, Trabajadora de Call Center).

El tema que por ahí siempre hay miedo, de no reclamar lo que te corresponde, o por ahí somos medios quedados, no nos asesoramos, entonces nos conformamos en ese sentido, y seguimos, y seguimos, y así... (...) ¡No podes hacer nada! Porque no tienen la capacidad o la gente para poder hacerlo. Está todo tan bien armado que no tenés opción a, digamos, siquiera a poder aportar algo, es decir, de tu parte que pueda ayudar a la causa. (Varón, 29 años, Trabajador de Call Center).

La amenaza, como el "rumor", constituye una extorsión constante e informe que imprime la incertidumbre en el "cuerpo precario", configurando una forma de sociabilidad que lo pone a disposición de los procesos de normalización y disciplinamiento. El miedo (miedo a que cierre la empresa, miedo a que me echen por reclamar) es el complemento solidario de la amenaza, que viene a consagrar la naturalización del riesgo, a partir de "hacer vivir" como algo personal la gestión de las posibilidades de neutralizar los peligros estructurales (del desempleo, de la baja calidad del empleo, etc.). Finalmente, la impotencia se despliega como el saldo de los mecanismos vinculados al miedo y la amenaza. La sensación de "no tener opción" y "estar obligado a seguir y seguir" no es una condición inherente al propio sujeto. Constituye el resultado de la naturalización de las condiciones estructurales, y deviene una de las formas específicas a partir de las cuales el miedo y la amenaza "marcan" a los "cuerpos precarios" y performan sus potencialidades de acción.

\section{CONCLUSIONES}

Recuperando la concepción de Santos (2011), si el Sur Global es definido como una metáfora del sufrimiento causado por la expansión del capitalismo, demarcando con dicha operación los bordes y abyecciones que apuntalan la re-producción de una sociedad colonizada por la mercantilización, es evidente que el dolor como emoción no puede ser escindido (ni analítica, ni política, ni existencialmente) del riesgo y la incertidumbre que moldean la vida-de-todoslos-días de los "cuerpos precarios" en dichas geografías. En otras palabras, en el marco de una sociedad estructurada desde la indeterminación que impone el capital, entendido éste no como un objeto sino como relaciones sociales basadas en la sistemática apropiación del disfrute del otro (Marx, 1867), en las escenas conflictuales estudiadas en este artículo puede observarse con claridad cómo la desposesión opera como lógica persistente de la estructura social.

Así, al explorar experiencias conflictivas de sujetos que habitan, respiran y trabajan en la intemperie, se comprende en qué sentido el cuerpo/emoción deviene un analizador de los procesos de estructuración en curso. Por un lado, porque constituye el epicentro de los mecanismos orientados a delimitar, marcar 
y gestionar la habitabilidad, la exposición al entorno medio ambiental y el trabajo. Por el otro, pero subsidiario del sentido anterior, porque las disputas que se "encarnan" en el cuerpo/emoción resultan indicadores de las formas en que se estructuran cotidianamente la dependencia y la heteronomía en los regímenes neo-coloniales.

De modo que la opción teórica sobre la que se organiza el análisis precedente se corresponde, estrictamente, con un posicionamiento metodológico y epistemológico según el cual observar los modos en que las sociedades gestionan, organizan y regulan la disposición social de los cuerpos/emociones, y cómo éstos se apropian y (re)significan dicha regulación en el marco de sus prácticas, es una vía analítica apropiada para examinar los procesos de estructuración social. En el marco de esta delimitación, el artículo se propuso mostrar que el cuerpo precario -comprendido como el resultado de los procesos de expropiación y como plataforma de las disputas por el habitar, respirar y trabajar- es un condensador analítico válido de las formas situadas en que la sociedad configura el riesgo, la incertidumbre y la precariedad.

Como se intentó mostrar en base al material empírico presentado, en los cuerpos precarios la intemperie se hace carne, mientras que la desprotección sistemática resulta en resignación y soportabilidad. Sea en la experiencia de habitar en condiciones de extrema privación, de vivir en la certeza de la contaminación y/o de con-vivir con el miedo y la amenaza permanente que obligan a "seguir y seguir", los cuerpos precarios están atravesados por la disposición (vivida como individual) de gestionar(se) la incertidumbre (estructural), en tanto marca de la vida propia y de las generaciones futuras.

En este marco, las escenas conflictuales estudiadas muestran que el riesgo no es un "estado" que configura a las sensibilidades y subjetividades, sino un "rasgo" estructural-estructurante de las sociedades contemporáneas. Rasgo que, desde una Sociología de los Cuerpos/Emociones, puede ser comprendido como una forma de sufrimiento social resultante del flujo de tribulaciones que se anteponen como parte del escenario de negaciones en que se vive y convive. De modo que habitar en la intemperie, respirar la contaminación y trabajar en condiciones de precariedad configuran un conjunto acumulado de desventajas que abonan la naturalización del riesgo y la incertidumbre como resultado de una reiterada (e inevitable) vivencia del sufrimiento en los "interiores" del "mundo del No". Y ello es, evidentemente, un aspecto nodal de las políticas de las sensibilidades en el actual escenario neocolonial.

\section{REFERENCIAS BIBLIOGRÁFICAS}

APPAY, B. y JEFFERYS, S. (Ed.) (2009): Restructuration, précarisation, valeurs, Toulouse, Octares.

BAUMAN, Z. (2009): Tiempos líquidos. Vivir en una época de incertidumbre, México, Tusquets. 
BECK, U. (1998): La sociedad del riesgo. Hacia una nueva modernidad, Barcelona, Paidós.

BECK, U. (2000): Un nuevo mundo feliz. Precariedad del trabajo en la era de la globalización, Barcelona, Paidós.

BECK, U; Giddens, A. y Lash, S. (1997): Modernización reflexiva. Política, tradición y estética en el orden social moderno, Madrid, Alianza.

BUTLER, J. (2006): Vida precaria: el poder del duelo y la violencia, Buenos Aires, Paidós.

CASTEL, R. (2013): "Políticas del riesgo y sentimiento de inseguridad", en Castel, R., Kessler, G., Merklen, D. y Murard, N. Individuación, precariedad, inseguridad ¿desinstitucionalización del presente?, Buenos Aires, Paidós, pp. 33-43.

CASTEL, R. (2007): “Au-delà de l'emploi, en-deçà du salariat, le précariat”, en Paugam, S. (Dir.) Repenser la solidarité, Paris, PUF.

CASTEL, R. (1997): Las metamorfosis de la cuestión social, Buenos Aires, Paidós.

CASTEL, R. y HAROCHE. C. (2001): Propiedad privada, propiedad social, propiedad de sí mismo. Conversaciones sobre la construcción del individuo moderno, Buenos Aires, HomoSapiens.

CERVIO, A. (Ed). (2012): Las tramas del sentir. Ensayos desde una sociología de los cuerpos y las emociones, Buenos Aires, ESEditora.

CERVIO, A. (2010): "Performatividad, fantasmas y fantasías sociales. El 'encantamiento’ de la (re)nominación en la gestión del hábitat social en la ciudad de Córdoba", Actuel Marx/Intervenciones, 9, pp.261-283.

CINGOLANI, P. (2014): "La idea de precariedad en la sociología francesa”, RELACES, 16 , pp. 48-55.

D'HERS, V. (2013): "Entre el amor y el espanto: Cuerpos del sufrimiento, la resistencia y el logro en barrios ambientalmente degradados", Revista Brasileira de Sociologia da Emoção, 12 (34), pp. 122-155.

DORRE, Klaus (2009): "La Precariedad: ¿Centro de la cuestión social en el Siglo XXI?, Actuel Marx, 8, pp. 79-108.

FUNDACION AMBIENTE Y RECURSOS NATURALES (FARN) (2010): Recomposición ambiental de la cuenca Matanza Riachuelo: Una oportunidad histórica que aún reclama un fuerte compromiso político y más eficiencia en la gestión. Informe ambiental anual, Buenos Aires, FARN.

GIDDENS, A. (1994): Consecuencias de la modernidad, Madrid, Alianza.

HARVEY, D. (2004): El nuevo imperialismo, Madrid, Akal.

LUHMANN, N. (2006): Sociología del riesgo, México, Universidad Iberoamericana.

LINDENBOIM, J. (2018): Radiografía de la precariedad laboral actual, disponible en https://www.lapoliticaonline.com/nota/javier-lindenboimradiografia-de-la-precariedad-laboral-actual/ [consulta: 03-06-2018].

LISDERO, P. (2009): “Cuerpos Recuperados / Cuerpos en Custodia. Una lectura sintomal de la acción colectiva de la Cooperativa Junín de Salud Limitada", en Scribano, A. y Fígari, C. (Comp.) Cuerpo(s), Subjetividad(es) y Conflicto(s) Hacia una sociología de los cuerpos y las emociones desde Latinoamérica, Buenos Aires, CLACSOCICCUS, pp. 101-118.

LOREY, I. (2008): “Gubernamentalidad y precarización de sí. Sobre la normalización de los productores y las productoras culturales", en Buden, B.; Butler, J; De Nicola, A. et al. Producción cultural y prácticas instituyentes. Líneas de ruptura en la crítica institucional, Madrid, Traficantes de sueños.

MARX, K. ([1867] 2001): El Capital. México: FCE. 
MELUCCI, A. (1996): Challenging Codes. Collective Action in the Information Age, Cambridge, Cambridge University Press.

MELUCCI, A. (2016): Cuerpos extraños, Buenos Aires, ESEditora.

OBSERVATORIO DE LA DEUDA SOCIAL ARGENTINA (ODSA) (2017): "Desarrollo Humano e Integración Social en la Argentina Urbana 2010-2016", Barómetro de la Deuda Social Argentina. Serie del Bicentenario (2010/2016)/Año VII, Buenos Aires, Universidad Católica Argentina.

ORGANIZACIÓN INTERNACIONAL DEL TRABAJO (OIT) (2012): Del trabajo precario al trabajo decente: documento final del simposio de los trabajadores sobre políticas y reglamentación para luchar contra el empleo precario, Ginebra, Oficina Internacional del Trabajo, Oficina de Actividades para los Trabajadores (ACTRAV).

ORGANIZACIÓN INTERNACIONAL DEL TRABAJO (OIT) (2018): Perspectivas Sociales y del Empleo en el Mundo 2018: Sostenibilidad medioambiental con empleo, Ginebra, Oficina Internacional del Trabajo.

SANTOS, B. de S. (2011): "Epistemologías del Sur", Utopía y praxis latinoamericana, 16 (54), pp. 17-39.

SCRIBANO, A. (2017): “Amor y acción colectiva: una mirada desde las prácticas intersticiales en la Argentina”, Aposta, Revista de Ciencias Sociales, 74, pp. 241-280.

SCRIBANO, A (comp) (2013): Teoría social, cuerpos y emociones, Buenos Aires, ESEditora.

SCRIBANO, A. (2009): “A modo de epílogo. ¿Por qué una mirada sociológica de los cuerpos y las emociones?”, en Scribano, A. y Fígari, C. (Comp.) Cuerpo(s), Subjetividad(es) y Conflicto(s) Hacia una sociología de los cuerpos y las emociones desde Latinoamérica, Buenos Aires, CLACSO-CICCUS, pp. 141-151.

SCRIBANO, A. (2004): Combatiendo fantasmas. Teoría social latinoamericana. Una visión desde la Historia, la Sociología y la Filosofía de la Ciencia, Santiago de Chile, Ediciones Mad.

SCRIBANO, A. y LISDERO, P. (Comp.) (2010): Sensibilidades en juego: miradas múltiples desde los estudios sociales de los cuerpos y las emociones, Buenos Aires, ESEditora.

VARELA, O. y CRAVINO, M (2008): "Mil nombres para mil barrios. Los asentamientos y villas como categorías de análisis y de intervención", en Cravino, M. (Org.) Los mil barrios (in)formales Aportes para la construcción de un observatorio del hábitat popular del Área Metropolitana de Buenos Aires, Buenos Aires, Universidad Nacional de General Sarmiento.

WAGNER, P. (1994): A sociology of modernity, London, Routledge. 
